\title{
Polish 2010 growth references for school-aged children and adolescents
}

\author{
Zbigniew Kułaga • Mieczysław Litwin • Marcin Tkaczyk • Iwona Palczewska • \\ Małgorzata Zajączkowska • Danuta Zwolińska • Tomasz Krynicki • \\ Anna Wasilewska • Anna Moczulska • Aurelia Morawiec-Knysak • \\ Katarzyna Barwicka • Aneta Grajda • Beata Gurzkowska • Ewelina Napieralska • \\ Huiqi Pan
}

Received: 19 July 2010 / Accepted: 5 October 2010 /Published online: 23 October 2010

(C) The Author(s) 2010. This article is published with open access at Springerlink.com

\begin{abstract}
Growth references are useful in monitoring a child's growth, which is an essential part of child care. The aim of this paper was to provide updated growth references for Polish school-aged children and adolescents and show the prevalence of overweight and obesity among them. Growth references for height, weight, and body mass index (BMI) were constructed with the lambda, mu, sigma (LMS)
\end{abstract}

Z. Kułaga $(\bowtie) \cdot$ M. Litwin $\cdot$ K. Barwicka $\cdot$ A. Grajda

B. Gurzkowska $\cdot$ E. Napieralska

The Children's Memorial Health Institute,

Al. Dzieci Polskich 20,

04-730 Warsaw, Poland

e-mail: z.kulaga@czd.pl

URL: www.czd.pl

M. Tkaczyk

Polish Mother's Memorial Hospital Research Institute,

Rzgowska 281/289,

93-338 Łódź, Poland

I. Palczewska

Institute of Industrial Design,

Świętojerska 3/5,

00-236 Warsaw, Poland

\section{Zajączkowska}

Department of Paediatric Nephrology, Lublin Medical University,

Chodźki 2,

20-093 Lublin, Poland

\section{Zwolińska}

Department of Paediatric Nephrology,

Wroclaw Medical University,

M. Skłodowskiej-Curie 50/52,

50-369 Wrocław, Poland method using data from a recent, large, populationrepresentative sample of school-aged children and adolescents in Poland $(n=17,573)$. The prevalence of overweight and obesity according to the International Obesity Taskforce definition was determined with the use of LMSGrowth software. Updated growth references for Polish school-aged children and adolescents were compared

T. Krynicki

Department of Pediatric Cardiology and Nephrology,

University School of Medical Sciences,

Szpitalna 2,

Poznań 60-572, Poland

A. Wasilewska

Department of Pediatrics, Medical University of Białystok,

Waszyngtona 17,

15-274 Białystok, Poland

A. Moczulska

Paediatric Nephrology Department,

Jagiellonian University Medical College,

Wielicka 265,

30-663 Kraków, Poland

A. Morawiec-Knysak

Paediatric Department, Medical University of Silesia,

3 Maja 13/15,

41-800 Zabrze, Poland

H. Pan

Centre of Epidemiology for Child Health,

UCL Institute of Child Health,

30 Guilford St.,

London WC1N 1EH, UK 
with Polish growth references from the 1980s, the Warsaw 1996-1999 reference, German, and 2000 CDC references. A positive secular trend in height was observed in children and adolescents from 7 to 15 years of age. A significant shift of the upper tail of the BMI distribution occurred, especially in Polish boys at younger ages. The prevalence of overweight or obesity was $18.7 \%$ and $14.1 \%$ in schoolaged boys and girls, respectively. The presented height, weight, and BMI references are based on a current, nationally representative sample of Polish children and adolescents without known disorders affecting growth. Changes in the body size of children and adolescents over the last three decades suggest an influence of the changing economical situation on anthropometric indices.

Keywords Children · Adolescents · Growth references . LMS method

\section{Introduction}

Human growth is under the control of both genetic and environmental influences. There is considerable variation across populations in height and weight, which is the result of genetic diversity, exposition to vastly different environmental factors, and differences in socioeconomic status $[19,36]$. A child's growth is an indicator of health [14] and society's wellbeing [35]. Monitoring growth to identify health- or nutrition-related problems is an important task of health care providers. In practice, growth references are used: (1) by medical professionals involved in the care of individual children as a part of medical assessment to evaluate the growth status of a child and (2) as a public health tool, to summarize and compare anthropometry among groups of children [5]. For optimal growth monitoring, up-to-date reference growth data on representative samples from the population are essential.

Immigration results in increased genetic variability of the population. Temporary or permanent migration in the modern world is also a challenge for public health in the perspective of assessing (immigrant) children's health. In view of the noticeable differences in height between ethnic groups, the dilemma arises whether one should use growth references derived from a representative sample from the whole (multiethnic) population or reference data on the largest ethnic groups; some immigration countries have adopted the second approach $[1,11$, 12, 18]. Poland, a net emigration country [31], does not have its own growth reference data constructed with a representative national sample of children and adolescents and regularly updated, for example, in 10-year intervals. The first height and weight data for the Polish population were published by Kosmowski and Suligowski in the nineteenth century [20,34]. Nationwide surveys, including children from rural areas, were conducted in the 1970s and 1980s [17, 37]. Since then, several growth references have been developed in Poland, but sampling was restricted to the populations of the largest cities, and, in the case of some of the references, sampling was not random. Some of the local Polish references were constructed without accounting for skewness of weight and body mass index (BMI) [27]. Both lack of national representativeness and construction drawbacks, with regard to variables not having a normal distribution, limit the use of local growth references, especially in a population undergoing rapid increases in the prevalence of overweight and obesity in children and adolescents [23]. In a contemporary sample of Polish school-aged children, distributions of height, weight, and BMI differed from those of children from international growth references [24]. In this paper, we present cross-sectional height, weight, and BMI references for school-aged children in Poland using data from a current sample of Polish children aged 6 to 19 years and compare the resultant, selected centiles with chosen growth references. We also took advantage of the large, population-representative sample to investigate the prevalence of overweight and obesity among children and adolescents in Poland.

\section{Materials and methods}

The analyzed data were collected in the course of the OLAF study (PL0080) in which reference blood pressure ranges were elaborated for Polish children and adolescents. Field examinations were conducted in 416 schools in all regions of Poland between November 2007 and November 2009.

\section{Subjects}

Study participants (children and adolescents 6-19 years of age) were randomly selected using two-stage sampling. Primary sampling units (schools) were sampled from an allschools-in-Poland sampling frame provided by the Polish Ministry of Education. Sampling was stratified by province and urban/rural area. In the second stage, all pupils in the required age ranges within the sampled schools comprised the sampling frame. Pupils in schools were selected for the survey by stratified random sampling, the stratification variables being classes. 
The medical history of the study participants, including past and present diseases, as well as medications used, was obtained from the parents by questionnaire. The questionnaire also included date of birth, birth weight, and social status. The general health status of each subject was assessed by a physician.

All subjects and their parents (in the case of subjects under 18 years of age) gave their informed consent to participate in the study (parents of all subjects under 18 years of age and subjects over 16 years of age gave written consent). Approval by the Children's Memorial Health Institute Ethics Committee to conduct the study was obtained before the study commenced.

\section{Anthropometric techniques}

Measurements were conducted in school nurses' offices from 8:00 $\mathrm{AM}$ to 3:00 $\mathrm{PM}$. All measurements were taken in duplicate by trained staff: anthropologists, nurses, public health professionals, and physicians using standard, calibrated equipment. Each study team consisted of two professionals. The exact ages of the participants were calculated from birth and examination dates.

Height was measured using a SECA 214 stadiometer. The subject was in the standing upright position (no shoes), with hips and shoulders perpendicular to the central axis, heels against the footboard, knees together, arms hanging loosely at the sides, and the head in the Frankfurt plane. Height was recorded to the nearest millimeter; if the difference between measurements exceeded $4 \mathrm{~mm}$, a third measurement was taken. Body weight was recorded in light underwear to the nearest $0.05 \mathrm{~kg}$, using a digital medical scale (Radwag WPT 100/200, Poland). In the case of a difference between measurements equal to or exceeding $0.3 \mathrm{~kg}$, a third measurement was taken. Body mass index was calculated as body weight divided by height in meters squared.

\section{Exclusion criteria}

Exclusion criteria were: posture deficiency, genetic syndromes (Down syndrome, Turner syndrome), cancer, or other chronic disease influencing height, including children treated with growth hormone or diagnosed with growth hormone deficiency, children treated with systemic steroids for any reason (asthma, arthritis, renal transplant recipients), diabetes, cerebral palsy, thyroid hormone supplementation, cystic fibrosis, renal disease, congenital adrenal hyperplasia, and congenital heart defect with impairment of physical fitness. In the case of pregnancy, data were excluded from the analysis of body weight and BMI, but not height. If a plaster cast was present and could not be removed for the measurements, thus interfering with the measurement result (e.g., plaster cast on foot), the data were also excluded from the analysis.

Statistical analysis

Data were recorded on paper forms and later transferred to a computer database. Data were cleaned and validated with SAS 9.2 using Proc Freq, Proc Standard, and Proc Univariate. Outliers, defined as values over 4 SDS or below $-4 \mathrm{SDS}$, were identified by inspecting the $z$-score plot of the variable under consideration. Outliers were checked carefully for possible mistakes of data recording and/or transfer. None of the outliers was considered to be biologically implausible, and there were no outlier exclusions from the dataset.

Centile curves for height, weight, and BMI were constructed separately for each sex using the lambda, mu, sigma (LMS) method [4] and LMSChartMaker Pro version 2.42 software [28]. A Box-Cox power transformation was used to normalize the data at each age. Natural cubic splines with knots at each distinct age $t$ were fitted by maximum penalized likelihood to create three smooth curves: $L(t)$ the Box-Cox power, $M(t)$ the median, and $S(t)$ the coefficient of variation. Centile curves at age were then obtained as

$C_{100 \alpha}(t)=M(t)\left[1+L(t) S(t) Z_{\alpha}\right]^{1 / L(t)}$

where $Z_{\alpha}$ is the normal equivalent deviate for tail area ${ }_{\alpha}$, and $C 100_{\alpha}(t)$ is the centile corresponding to $Z_{\alpha}$. Equivalent degrees of freedom (edf) $L(t), M(t)$, and $S(t)$ measure the complexity of each fitted curve. Q tests [29, 33] were used to check the goodness of fit. The $z$-score for a given measurement and age in the reference range can be obtained by inverting the above equation.

Subjects aged 6 to 19 years were included for the construction of reference centiles and $z$-scores but, due to the small number of study participants aged 6 and 19 years, only results from 7 to 18 years of age are presented here.

In the case of height, in addition to the traditional set of centiles (third, tenth, 25th, 50th, 75th, 90th, 97th), the fifth and 95th centiles were fitted to enable interpretation of blood pressure measurements, for which reference values are developed for age and height centile. In the case of weight and BMI, the 85 th centile was additionally included because this is the recommended BMI cutoff identifying children and adolescents at risk for overweight in some 
countries, for example the USA [2]. The prevalence of overweight and obesity according to the International Obesity Taskforce (IOTF) definition [7] was determined with the use of LMSGrowth software [13].

Study quality measures

All measurements were taken by trained staff. The training consisted of workshops for study teams, during which the standardized measuring technique was presented (lecture, visuals) and taught (practical exercises). Following the workshop, in-the-field standardization sessions were conducted according to the standardization protocol. Reliability of anthropometric measurements between the trainer and the trainee (study staff) was documented. After 10 months of conducting the study, re-training of study teams was carried out.

The data were processed centrally. Data entry was performed by trained staff, according to the data entry manual.
All entries were checked by a different person against source data (case report form, parent's questionnaire). Based on the data quality monitoring, research teams were informed of the need to take corrective action(s). Data queries were solved by contacting regional investigators or parents directly. In the case of an unresolved data query, the data was classified as missing. Visiting regional research teams during the measurement sessions was undertaken by the study coordinator staff to ensure compliance with the study protocol.

Comparison with chosen growth references

Based on comparability with regard to statistical methods of constructing reference growth charts and on historical usage, the third, 50th, and 97th centiles were selected to compare with growth references for: Warsaw school-aged children from the late 1990s [27], German children and adolescents [21], and 2000 Centers for Disease Control and Prevention (2000 CDC) growth charts [22].

Table 1 Polish 2010 height $(\mathrm{cm})$ reference values for school-aged children and adolescents by age and sex

\begin{tabular}{|c|c|c|c|c|c|c|c|c|c|c|c|c|c|}
\hline \multirow[t]{2}{*}{ Age (years) } & \multirow[t]{2}{*}{ Number } & \multicolumn{3}{|c|}{ LMS } & \multicolumn{9}{|c|}{ Centiles } \\
\hline & & $\mathrm{L}$ & M & S & Third & Fifth & Tenth & 25 th & 50 th & 75th & 90th & 95th & 97th \\
\hline \multicolumn{14}{|l|}{ Boys } \\
\hline 7 & 450 & 1 & 124.5763 & 0.0407 & 115.0 & 116.2 & 118.1 & 121.2 & 124.6 & 128.0 & 131.1 & 132.9 & 134.1 \\
\hline 8 & 715 & 1 & 130.5084 & 0.0422 & 120.1 & 121.4 & 123.4 & 126.8 & 130.5 & 134.2 & 137.6 & 139.6 & 140.9 \\
\hline 9 & 731 & 1 & 136.2700 & 0.0441 & 125.0 & 126.4 & 128.6 & 132.2 & 136.3 & 140.3 & 144.0 & 146.2 & 147.6 \\
\hline 10 & 648 & 1 & 141.4685 & 0.0457 & 129.3 & 130.8 & 133.2 & 137.1 & 141.5 & 145.8 & 149.8 & 152.1 & 153.6 \\
\hline 11 & 665 & 1 & 146.7490 & 0.0473 & 133.7 & 135.3 & 137.9 & 142.1 & 146.7 & 151.4 & 155.6 & 158.2 & 159.8 \\
\hline 12 & 638 & 1 & 152.9406 & 0.0499 & 138.6 & 140.4 & 143.2 & 147.8 & 152.9 & 158.1 & 162.7 & 165.5 & 167.3 \\
\hline 13 & 640 & 1 & 160.2044 & 0.0511 & 144.8 & 146.7 & 149.7 & 154.7 & 160.2 & 165.7 & 170.7 & 173.7 & 175.6 \\
\hline 14 & 668 & 1 & 167.2116 & 0.0481 & 152.1 & 154.0 & 156.9 & 161.8 & 167.2 & 172.6 & 177.5 & 180.5 & 182.3 \\
\hline 15 & 722 & 1 & 172.4996 & 0.0430 & 158.5 & 160.3 & 163.0 & 167.5 & 172.5 & 177.5 & 182.0 & 184.7 & 186.5 \\
\hline 16 & 690 & 1 & 175.7266 & 0.0392 & 162.8 & 164.4 & 166.9 & 171.1 & 175.7 & 180.4 & 184.6 & 187.1 & 188.7 \\
\hline 17 & 801 & 1 & 177.6036 & 0.0370 & 165.2 & 166.8 & 169.2 & 173.2 & 177.6 & 182.0 & 186.0 & 188.4 & 190.0 \\
\hline 18 & 846 & 1 & 178.6756 & 0.0357 & 166.7 & 168.2 & 170.5 & 174.4 & 178.7 & 183.0 & 186.9 & 189.2 & 190.7 \\
\hline \multicolumn{14}{|l|}{ Girls } \\
\hline 7 & 389 & 1 & 123.0195 & 0.0419 & 113.3 & 114.5 & 116.4 & 119.5 & 123.0 & 126.5 & 129.6 & 131.5 & 132.7 \\
\hline 8 & 693 & 1 & 129.3683 & 0.0440 & 118.7 & 120.0 & 122.1 & 125.5 & 129.4 & 133.2 & 136.7 & 138.7 & 140.1 \\
\hline 9 & 701 & 1 & 135.2446 & 0.0457 & 123.6 & 125.1 & 127.3 & 131.1 & 135.2 & 139.4 & 143.2 & 145.4 & 146.9 \\
\hline 10 & 748 & 1 & 140.7839 & 0.0471 & 128.3 & 129.9 & 132.3 & 136.3 & 140.8 & 145.3 & 149.3 & 151.7 & 153.3 \\
\hline 11 & 673 & 1 & 147.1313 & 0.0472 & 134.1 & 135.7 & 138.2 & 142.5 & 147.1 & 151.8 & 156.0 & 158.5 & 160.2 \\
\hline 12 & 636 & 1 & 153.8132 & 0.0444 & 141.0 & 142.6 & 145.1 & 149.2 & 153.8 & 158.4 & 162.6 & 165.0 & 166.6 \\
\hline 13 & 644 & 1 & 159.0773 & 0.0406 & 146.9 & 148.5 & 150.8 & 154.7 & 159.1 & 163.4 & 167.4 & 169.7 & 171.2 \\
\hline 14 & 754 & 1 & 162.2376 & 0.0380 & 150.6 & 152.1 & 154.3 & 158.1 & 162.2 & 166.4 & 170.1 & 172.4 & 173.8 \\
\hline 15 & 709 & 1 & 163.7435 & 0.0368 & 152.4 & 153.8 & 156.0 & 159.7 & 163.7 & 167.8 & 171.5 & 173.7 & 175.1 \\
\hline 16 & 817 & 1 & 164.3511 & 0.0363 & 153.1 & 154.5 & 156.7 & 160.3 & 164.4 & 168.4 & 172.0 & 174.2 & 175.6 \\
\hline 17 & 1,058 & 1 & 164.7437 & 0.0360 & 153.6 & 155.0 & 157.1 & 160.7 & 164.7 & 168.7 & 172.3 & 174.5 & 175.9 \\
\hline 18 & 1,126 & 1 & 165.0598 & 0.0358 & 154.0 & 155.4 & 157.5 & 161.1 & 165.1 & 169.0 & 172.6 & 174.8 & 176.2 \\
\hline
\end{tabular}




\section{Results}

There were 24,814 pupils drawn and invited to take part in the study, of whom 17,573 children and adolescents $(8,396$ boys) consented and were enrolled (response rate 0.71). Forty percent of study subjects were attending primary or secondary schools located in rural areas, which reflects the national proportions. The distribution of demographic and social variables in the sample was relatively close to available national statistics [3] for mothers' education (18\% higher education, 38\% secondary education, 32\% vocational education, $8 \%$ primary education), family size (66\% subjects in the study came from families with one or two children), parenthood (13\% single), source of family income (58\% employment, $8 \%$ self-employment, $7 \%$ social security benefits or pension, $8 \%$ farmers, $19 \%$ other or combination of previously listed).

Anthropometric data were excluded from the analysis in the case of 123 boys and 164 girls who fulfilled exclusion criteria. Height measurements were missing in the case of three boys and two girls. Seven women in the sample were pregnant, and their data on weight and, consequently BMI, were excluded from the weight and BMI analysis, but kept for the height analysis. Weight measurements were missing in the case of three boys and three girls. Data from one woman aged 19.5 years were not included because of age extreme in the sample. Finally, data from 8,270 boys and 9,010 girls aged 6-19 years were used for constructing height references. Weight and BMI references were developed with the use of data from 8,267 boys and 9,000 girls.

\section{Height}

The reference height centiles for boys and girls were constructed without skewness. The Box-Cox power transformations $L$ for height were set to 1 at all ages. The height edf parameters were: $L 0(1) \mathrm{M} 7 \mathrm{~S} 5$, and $L 0(1) \mathrm{M} 7 \mathrm{~S} 4$, boys and girls, respectively ( $L, M, S$ stand for: the Box-Cox power of transformation, the median, and the coefficient of variation, respectively; the number after the symbol is the value of $e d f$ ). Since height changed with age monotonously, we used the age rescaled function in the LMSChartMaker, which improves the fit. Table 1 shows height references by age in boys and girls. Contemporary Polish boys in the age range of 7-15 years were about $1 \mathrm{~cm}$ taller compared with their counterparts from the late 1990s in Warsaw; however, at ages $16-18$ years, they were $0.1-0.9 \mathrm{~cm}$ shorter [27]. In comparing the 50th centile of Polish children with their peers in Germany [21], it is worth noting that, at ages 1518 years, Polish adolescents were, on average, $1-3 \mathrm{~cm}$ shorter (both boys and girls). The opposite is observed at ages 7-14 years: the differences were smaller and, in some

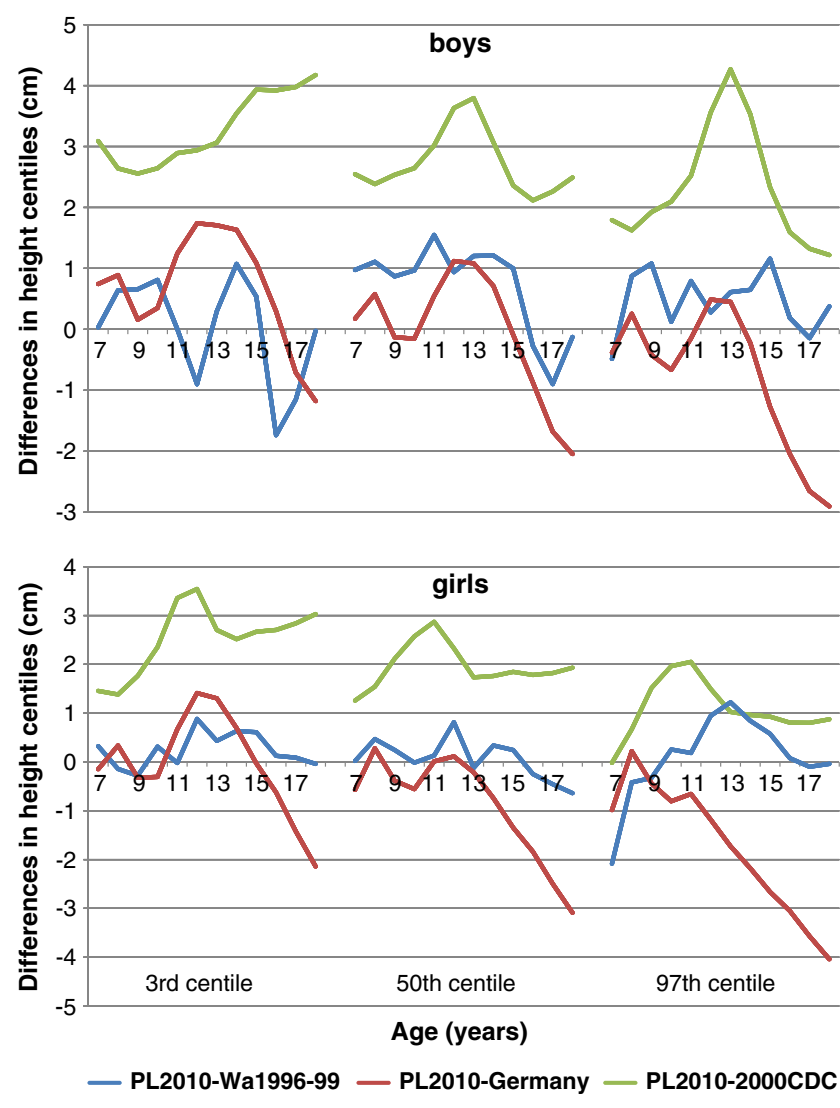

Fig. 1 Comparison of selected centiles of four height references. PL2010 reported OLAF study height references, PL1996-99 Warsaw height references [24], Germany height references for German children and adolescents [18], 2000CDC height references of the Centers for Disease Control and Prevention [19]

ages, Polish children (especially boys) were taller (0.2$0.7 \mathrm{~cm}$ ) than their German counterparts. A similar pattern was noted in the third and 97th centiles: younger Polish children were equally tall or taller than their German peers, whereas in the older ages, German adolescents were taller than Polish ones. On the third, 50th, and 97th centiles, Polish boys and girls were up to $4.3 \mathrm{~cm}$ taller compared with their American peers [22] (Fig. 1).

\section{Weight}

Table 2 shows weight references by age in boys and girls. The weight edf parameters were: L3M5S4, and L4M6S5, boys and girls, respectively. Similarly, as in the case of height, age was rescaled in the weight reference construction. Positive skewness was observed in all ages; smoothed $L$ values for weight varied between -1.35 and -0.53 . Comparison between the 2010 Polish and the Warsaw weight references and between the 2010 Polish and the German weight references showed relative conformity on the third and 50th centile (both boys and girls). On the 97th 
Table 2 Polish 2010 weight $(\mathrm{kg})$ reference values for school-aged children and adolescents by age and sex

\begin{tabular}{|c|c|c|c|c|c|c|c|c|c|c|c|c|c|c|c|}
\hline \multirow[t]{2}{*}{ Age (years) } & \multirow[t]{2}{*}{ Number } & \multicolumn{3}{|l|}{ LMS } & \multicolumn{11}{|c|}{ Centiles } \\
\hline & & $\mathrm{L}$ & M & $\mathrm{S}$ & Third & Fifth & Tenth & 15 th & 25 th & 50 th & 75th & 85 th & 90th & 95 th & 97th \\
\hline \multicolumn{16}{|l|}{ Boys } \\
\hline 7 & 450 & -1.3451 & 24.4425 & 0.1739 & 18.6 & 19.2 & 20.1 & 20.8 & 21.9 & 24.4 & 27.8 & 30.0 & 31.9 & 35.1 & 37.6 \\
\hline 8 & 715 & -1.2241 & 27.5948 & 0.1853 & 20.6 & 21.3 & 22.4 & 23.2 & 24.6 & 27.6 & 31.6 & 34.3 & 36.5 & 40.4 & 43.5 \\
\hline 9 & 731 & -1.1007 & 30.8200 & 0.1969 & 22.6 & 23.4 & 24.7 & 25.6 & 27.2 & 30.8 & 35.6 & 38.8 & 41.4 & 46.0 & 49.6 \\
\hline 10 & 648 & -0.9733 & 34.2322 & 0.2077 & 24.6 & 25.5 & 27.0 & 28.2 & 30.0 & 34.2 & 39.8 & 43.6 & 46.6 & 51.9 & 56.0 \\
\hline 11 & 665 & -0.8410 & 38.1082 & 0.2164 & 26.9 & 27.9 & 29.7 & 31.0 & 33.2 & 38.1 & 44.5 & 48.9 & 52.3 & 58.2 & 62.7 \\
\hline 12 & 638 & -0.7093 & 42.7117 & 0.2205 & 29.7 & 30.9 & 33.0 & 34.6 & 37.1 & 42.7 & 50.0 & 54.8 & 58.6 & 65.0 & 69.8 \\
\hline 13 & 640 & -0.6043 & 48.1026 & 0.2164 & 33.4 & 34.8 & 37.2 & 39.0 & 41.8 & 48.1 & 56.0 & 61.2 & 65.2 & 71.8 & 76.7 \\
\hline 14 & 667 & -0.5548 & 53.7776 & 0.2034 & 38.0 & 39.6 & 42.2 & 44.1 & 47.1 & 53.8 & 62.0 & 67.3 & 71.3 & 77.9 & 82.7 \\
\hline 15 & 722 & -0.5641 & 59.0021 & 0.1864 & 42.8 & 44.5 & 47.2 & 49.1 & 52.3 & 59.0 & 67.2 & 72.4 & 76.3 & 82.6 & 87.2 \\
\hline 16 & 689 & -0.6093 & 63.3307 & 0.1716 & 47.2 & 48.8 & 51.5 & 53.5 & 56.6 & 63.3 & 71.4 & 76.4 & 80.2 & 86.3 & 90.7 \\
\hline 17 & 801 & -0.6625 & 66.8807 & 0.1601 & 50.8 & 52.5 & 55.2 & 57.1 & 60.3 & 66.9 & 74.8 & 79.7 & 83.4 & 89.3 & 93.6 \\
\hline 18 & 845 & -0.7110 & 69.8692 & 0.1510 & 53.9 & 55.6 & 58.3 & 60.2 & 63.3 & 69.9 & 77.7 & 82.5 & 86.0 & 91.8 & 95.9 \\
\hline \multicolumn{16}{|l|}{ Girls } \\
\hline 7 & 389 & -1.0642 & 23.4756 & 0.1703 & 17.8 & 18.4 & 19.3 & 20.0 & 21.1 & 23.5 & 26.5 & 28.5 & 30.1 & 32.7 & 34.7 \\
\hline 8 & 693 & -1.0484 & 26.6216 & 0.1825 & 19.9 & 20.5 & 21.6 & 22.4 & 23.7 & 26.6 & 30.4 & 32.9 & 34.8 & 38.2 & 40.7 \\
\hline 9 & 701 & -0.9785 & 29.9233 & 0.1940 & 21.9 & 22.7 & 24.0 & 24.9 & 26.5 & 29.9 & 34.4 & 37.4 & 39.8 & 43.9 & 47.0 \\
\hline 10 & 748 & -0.8443 & 33.5526 & 0.2050 & 24.0 & 24.9 & 26.5 & 27.6 & 29.4 & 33.6 & 38.9 & 42.4 & 45.2 & 49.9 & 53.5 \\
\hline 11 & 673 & -0.6766 & 37.8737 & 0.2133 & 26.6 & 27.6 & 29.5 & 30.8 & 33.0 & 37.9 & 44.1 & 48.1 & 51.2 & 56.5 & 60.5 \\
\hline 12 & 636 & -0.5461 & 42.8172 & 0.2095 & 30.0 & 31.2 & 33.3 & 34.9 & 37.4 & 42.8 & 49.6 & 54.0 & 57.2 & 62.7 & 66.7 \\
\hline 13 & 643 & -0.5460 & 47.6669 & 0.1936 & 34.2 & 35.5 & 37.8 & 39.4 & 42.0 & 47.7 & 54.6 & 59.0 & 62.2 & 67.6 & 71.5 \\
\hline 14 & 754 & -0.7062 & 51.3003 & 0.1742 & 38.2 & 39.5 & 41.7 & 43.3 & 45.8 & 51.3 & 58.0 & 62.2 & 65.4 & 70.7 & 74.5 \\
\hline 15 & 709 & -0.9209 & 53.6394 & 0.1589 & 41.2 & 42.4 & 44.5 & 46.0 & 48.4 & 53.6 & 60.0 & 64.1 & 67.2 & 72.3 & 76.1 \\
\hline 16 & 816 & -1.0647 & 54.9580 & 0.1506 & 42.9 & 44.1 & 46.1 & 47.6 & 49.9 & 55.0 & 61.2 & 65.2 & 68.2 & 73.3 & 77.0 \\
\hline 17 & 1,055 & -1.1518 & 55.7267 & 0.1461 & 43.9 & 45.1 & 47.0 & 48.5 & 50.8 & 55.7 & 61.9 & 65.8 & 68.8 & 73.8 & 77.5 \\
\hline 18 & 1,121 & -1.2035 & 56.1779 & 0.1434 & 44.5 & 45.6 & 47.6 & 49.0 & 51.3 & 56.2 & 62.3 & 66.2 & 69.1 & 74.1 & 77.8 \\
\hline
\end{tabular}

centile, however, Polish boys (especially at younger ages) weighed significantly more than their German counterparts and at older ages, significantly more than their peers from Warsaw in the late 1990s. An analogous finding (but to a lesser extent) concerns comparison of the 97th weight centile in the case of girls. A similar pattern of conformity and differences between centiles is seen in the comparison with the $2000 \mathrm{CDC}$ weight reference, with the only important difference being found in girls over 13 years of age on the 97th centile: Polish girls weighed significantly less compared with their American peers (Fig. 2).

Body mass index

Table 3 shows BMI references by age in boys and girls. As in the case of weight distribution, BMI distribution was skewed to the right in all ages. The smoothed $L$ values for the BMI varied from -2.22 to -1.34 . The BMI edf parameters were L2M5S5 and L3M5S5, boys and girls, respectively; age was rescaled. The BMI of $25 \mathrm{~kg} / \mathrm{m}^{2}$ at age 18 years was $z$-score +1.31 in females corresponding to the 90.5th centile and $z$-score +0.95 in males, on the 82.9 th centile. The adult obesity cutoff, BMI of $30 \mathrm{~kg} / \mathrm{m}^{2}$, at age 18 years was $z$-score +2.21 (corresponding to the 98.6th centile) and $z$-score +1.96 (corresponding to the 97.5th centile), for females and males, respectively. Comparison of the 2010 Polish BMI reference with the Warsaw, German, and 2000 CDC BMI references showed a high degree of concordance on the third and the 50th centile (both boys and girls). The 2010 Polish boys 97th BMI centile was consistently higher: $0.7-2.5$ units and $0.3-2.5$ units compared with the Warsaw reference [27] and the German reference [21], respectively. In the case of the $2000 \mathrm{CDC}$ reference [22], the 2010 Polish boys 97th BMI centile was higher (0.8-2.1 units) in the age range 7-13 years, but lower (from -1.1 to -0.1 units) in the age range 14 18 years. In the case of girls, the difference of the 2010 Polish reference 97th BMI centile with the Warsaw 

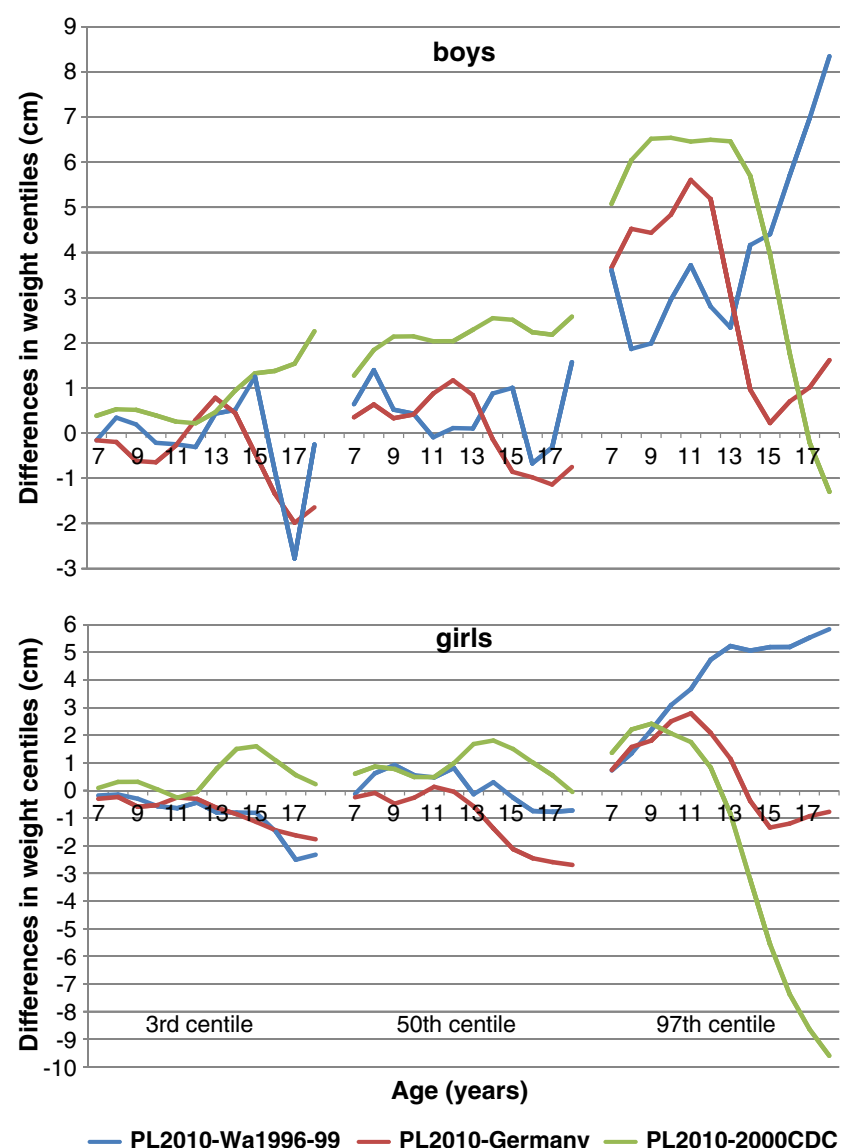

Fig. 2 Comparison of selected centiles of four weight references. PL2010 reported OLAF study weight references, PL1996-99 Warsaw weight references [24], Germany weight references for German children and adolescents [18], 2000CDC weight references of the Centers for Disease Control and Prevention [19]

reference and the German reference fluctuated in the range of: from -0.2 to 1.8 units, and from 0.1 to 1.0 units, respectively. The 97th BMI centile was lower in Polish girls aged over 9 years by up to 5.2 units in comparison with US counterparts (Fig. 3).

The prevalence of overweight and obesity

The prevalence of overweight and obesity among children and adolescents in 2007-2009 in Poland is shown in Table 4 . The prevalence of overweight or obesity by age and sex ranged from $9.1 \%$ of girls aged 16 years through $22.4 \%$ of boys aged 12 years.

\section{Discussion}

This paper provides updated growth references for Polish school-aged children and adolescents. The height, weight, and BMI references were constructed using data from a contemporary, cross-sectional, nationally representative sample. The sampling scheme resulted in accurate social and geographical representativeness of the sample. Although, in the growth references construction process, we excluded data from children with known disorders affecting growth, the presented charts and centiles should be considered as a growth reference not a growth standard because we have not identified optimal growth circumstances with regard to environmental influences. The LMS method (used for the first time to construct nationally representative growth references of Polish school-aged children and adolescents) has certain advantages in dealing with skewed data in construction of growth references. First, extreme centiles can be estimated more efficiently, second, any required centile can be calculated, and third, each observation can be converted to its standard deviation score $(z)$ with the formula

$Z=\frac{\left[\frac{\text { measurement }}{M}\right]^{L}-1}{L S}$ if $L \neq 0, Z=\log \frac{\left[\frac{\text { measurement }}{M}\right]}{S}$ if $L=0$,

( $L=$ Box-Cox power; $M=$ median; $S=$ coefficient of variation). This leads to simplification in the analysis of anthropometric data [5] and enables using more sensitive threshold for growth monitoring, for example, from -3 to -2 height $z$-score, which has recently been recommended by Dutch researchers [15].

According to the recent classification of the International Monetary Fund, Poland belongs to "emerging and developing economies" [38]. The economical situation of the society has improved gradually through the 1990s and in connection with joining the European Union (EU) in 2004. The improving economy has resulted in better living conditions and (possibly) improved conditions for children's growth. It seems, however, that, in the context of growth and development, the main beneficiaries were younger children, since until 2003 the per capita Gross Domestic Product (GDP) was below 50\% of the EU average [9]. According to the data provided by the Organisation for Economic Co-operation and Development (OECD) [26], Poland's GDP increased several-fold from the early 1990s (when the 16-18-year-old subjects of the OLAF study sample were born) to the years 1998-2002 (when the 6-10 year- old subjects of the OLAF study sample were born). GDP growth from a very low level to half of the EU average could be an explanation for the differences in body size between younger and older subjects in the OLAF sample, revealed in comparison with children and adolescents from Germany. This relation may also indicate that early stages of development, i.e., the first years of life, are very susceptible to any negative factors (e.g., economical hardship) and critical for achieved height [25]. 
Table 3 Polish 2010 BMI $\left(\mathrm{kg} / \mathrm{m}^{\wedge} 2\right)$ reference values for school-aged children and adolescents by age and sex

\begin{tabular}{|c|c|c|c|c|c|c|c|c|c|c|c|c|c|c|}
\hline \multirow[t]{2}{*}{ Age (years) } & \multicolumn{3}{|l|}{ LMS } & \multicolumn{11}{|c|}{ Centiles } \\
\hline & $\mathrm{L}$ & M & S & 3 & 5 & 10 & 15 & 25 & 50 & 75 & 85 & 90 & 95 & 97 \\
\hline \multicolumn{15}{|l|}{ Boys } \\
\hline 7 & -2.22 & 15.8 & 0.119 & 13.2 & 13.4 & 13.8 & 14.2 & 14.7 & 15.8 & 17.3 & 18.2 & 19.0 & 20.4 & 21.5 \\
\hline 7.5 & -2.19 & 16.0 & 0.124 & 13.3 & 13.5 & 14.0 & 14.3 & 14.8 & 16.0 & 17.6 & 18.6 & 19.5 & 21.0 & 22.2 \\
\hline 8 & -2.16 & 16.2 & 0.129 & 13.3 & 13.6 & 14.1 & 14.4 & 15.0 & 16.2 & 17.9 & 19.0 & 19.9 & 21.6 & 22.9 \\
\hline 8.5 & -2.13 & 16.4 & 0.135 & 13.4 & 13.7 & 14.2 & 14.5 & 15.1 & 16.4 & 18.2 & 19.4 & 20.4 & 22.2 & 23.7 \\
\hline 9 & -2.09 & 16.7 & 0.140 & 13.5 & 13.8 & 14.3 & 14.7 & 15.3 & 16.7 & 18.5 & 19.8 & 20.8 & 22.8 & 24.4 \\
\hline 9.5 & -2.06 & 16.9 & 0.144 & 13.6 & 13.9 & 14.4 & 14.8 & 15.5 & 16.9 & 18.8 & 20.2 & 21.3 & 23.4 & 25.1 \\
\hline 10 & -2.03 & 17.1 & 0.148 & 13.7 & 14.0 & 14.6 & 15.0 & 15.6 & 17.1 & 19.1 & 20.6 & 21.7 & 23.9 & 25.8 \\
\hline 10.5 & -1.99 & 17.3 & 0.151 & 13.8 & 14.2 & 14.7 & 15.1 & 15.8 & 17.3 & 19.4 & 20.9 & 22.2 & 24.5 & 26.4 \\
\hline 11 & -1.96 & 17.6 & 0.154 & 14.0 & 14.3 & 14.9 & 15.3 & 16.0 & 17.6 & 19.7 & 21.3 & 22.5 & 24.9 & 26.9 \\
\hline 11.5 & -1.92 & 17.8 & 0.155 & 14.1 & 14.5 & 15.1 & 15.5 & 16.2 & 17.8 & 20.0 & 21.6 & 22.9 & 25.3 & 27.3 \\
\hline 12 & -1.88 & 18.1 & 0.155 & 14.3 & 14.7 & 15.3 & 15.7 & 16.4 & 18.1 & 20.3 & 21.9 & 23.2 & 25.6 & 27.6 \\
\hline 12.5 & -1.84 & 18.3 & 0.154 & 14.5 & 14.9 & 15.5 & 15.9 & 16.7 & 18.3 & 20.6 & 22.2 & 23.5 & 25.8 & 27.8 \\
\hline 13 & -1.80 & 18.6 & 0.152 & 14.8 & 15.1 & 15.8 & 16.2 & 16.9 & 18.6 & 20.9 & 22.4 & 23.7 & 26.0 & 27.8 \\
\hline 13.5 & -1.76 & 18.9 & 0.149 & 15.1 & 15.4 & 16.0 & 16.5 & 17.2 & 18.9 & 21.1 & 22.6 & 23.9 & 26.1 & 27.8 \\
\hline 14 & -1.72 & 19.2 & 0.146 & 15.3 & 15.7 & 16.3 & 16.8 & 17.5 & 19.2 & 21.4 & 22.9 & 24.1 & 26.2 & 27.8 \\
\hline 14.5 & -1.67 & 19.5 & 0.143 & 15.6 & 16.0 & 16.6 & 17.1 & 17.8 & 19.5 & 21.7 & 23.1 & 24.3 & 26.3 & 27.8 \\
\hline 15 & -1.63 & 19.8 & 0.140 & 15.9 & 16.3 & 16.9 & 17.4 & 18.1 & 19.8 & 21.9 & 23.4 & 24.5 & 26.4 & 27.9 \\
\hline 15.5 & -1.58 & 20.1 & 0.138 & 16.2 & 16.6 & 17.2 & 17.7 & 18.4 & 20.1 & 22.2 & 23.7 & 24.8 & 26.7 & 28.1 \\
\hline 16 & -1.53 & 20.4 & 0.136 & 16.5 & 16.9 & 17.5 & 18.0 & 18.8 & 20.4 & 22.6 & 24.0 & 25.1 & 26.9 & 28.3 \\
\hline 16.5 & -1.49 & 20.8 & 0.135 & 16.8 & 17.2 & 17.8 & 18.3 & 19.1 & 20.8 & 22.9 & 24.3 & 25.4 & 27.2 & 28.6 \\
\hline 17 & -1.44 & 21.1 & 0.134 & 17.0 & 17.4 & 18.1 & 18.6 & 19.4 & 21.1 & 23.3 & 24.7 & 25.7 & 27.6 & 28.9 \\
\hline 17.5 & -1.39 & 21.5 & 0.134 & 17.3 & 17.7 & 18.4 & 18.9 & 19.7 & 21.5 & 23.6 & 25.0 & 26.1 & 27.9 & 29.2 \\
\hline 18 & -1.34 & 21.8 & 0.133 & 17.5 & 18.0 & 18.7 & 19.2 & 20.0 & 21.8 & 23.9 & 25.3 & 26.4 & 28.2 & 29.5 \\
\hline \multicolumn{15}{|l|}{ Girls } \\
\hline 7 & -2.06 & 15.5 & 0.119 & 12.9 & 13.2 & 13.6 & 13.9 & 14.4 & 15.5 & 17.0 & 17.9 & 18.7 & 20.0 & 21.0 \\
\hline 7.5 & -1.99 & 15.7 & 0.124 & 13.0 & 13.3 & 13.7 & 14.0 & 14.6 & 15.7 & 17.3 & 18.3 & 19.1 & 20.5 & 21.6 \\
\hline 8 & -1.93 & 16.0 & 0.129 & 13.1 & 13.4 & 13.8 & 14.2 & 14.7 & 16.0 & 17.6 & 18.6 & 19.5 & 21.0 & 22.2 \\
\hline 8.5 & -1.86 & 16.2 & 0.134 & 13.2 & 13.4 & 13.9 & 14.3 & 14.9 & 16.2 & 17.9 & 19.0 & 19.9 & 21.5 & 22.7 \\
\hline 9 & -1.79 & 16.4 & 0.139 & 13.2 & 13.5 & 14.1 & 14.4 & 15.0 & 16.4 & 18.2 & 19.4 & 20.3 & 22.0 & 23.3 \\
\hline 9.5 & -1.72 & 16.7 & 0.143 & 13.3 & 13.7 & 14.2 & 14.6 & 15.2 & 16.7 & 18.5 & 19.8 & 20.8 & 22.5 & 23.9 \\
\hline 10 & -1.66 & 16.9 & 0.147 & 13.5 & 13.8 & 14.3 & 14.8 & 15.4 & 16.9 & 18.8 & 20.2 & 21.2 & 23.0 & 24.5 \\
\hline 10.5 & -1.59 & 17.2 & 0.151 & 13.6 & 13.9 & 14.5 & 14.9 & 15.6 & 17.2 & 19.2 & 20.5 & 21.6 & 23.5 & 25.0 \\
\hline 11 & -1.53 & 17.5 & 0.153 & 13.8 & 14.1 & 14.7 & 15.1 & 15.9 & 17.5 & 19.5 & 20.9 & 22.0 & 24.0 & 25.5 \\
\hline 11.5 & -1.48 & 17.8 & 0.154 & 13.9 & 14.3 & 14.9 & 15.4 & 16.1 & 17.8 & 19.9 & 21.3 & 22.4 & 24.4 & 26.0 \\
\hline 12 & -1.44 & 18.1 & 0.154 & 14.2 & 14.6 & 15.2 & 15.7 & 16.4 & 18.1 & 20.2 & 21.7 & 22.8 & 24.8 & 26.3 \\
\hline 12.5 & -1.42 & 18.4 & 0.153 & 14.5 & 14.9 & 15.5 & 16.0 & 16.7 & 18.4 & 20.6 & 22.0 & 23.2 & 25.1 & 26.6 \\
\hline 13 & -1.42 & 18.8 & 0.150 & 14.8 & 15.2 & 15.8 & 16.3 & 17.1 & 18.8 & 20.9 & 22.4 & 23.5 & 25.4 & 26.9 \\
\hline 13.5 & -1.43 & 19.1 & 0.147 & 15.1 & 15.5 & 16.2 & 16.7 & 17.4 & 19.1 & 21.3 & 22.7 & 23.8 & 25.7 & 27.2 \\
\hline 14 & -1.46 & 19.4 & 0.143 & 15.5 & 15.9 & 16.5 & 17.0 & 17.7 & 19.4 & 21.6 & 23.0 & 24.1 & 25.9 & 27.4 \\
\hline 14.5 & -1.50 & 19.7 & 0.139 & 15.8 & 16.2 & 16.8 & 17.3 & 18.0 & 19.7 & 21.8 & 23.2 & 24.3 & 26.1 & 27.5 \\
\hline 15 & -1.54 & 19.9 & 0.136 & 16.1 & 16.5 & 17.1 & 17.5 & 18.3 & 19.9 & 22.0 & 23.4 & 24.4 & 26.2 & 27.6 \\
\hline 15.5 & -1.58 & 20.1 & 0.133 & 16.3 & 16.7 & 17.3 & 17.8 & 18.5 & 20.1 & 22.2 & 23.5 & 24.5 & 26.3 & 27.6 \\
\hline 16 & -1.62 & 20.3 & 0.130 & 16.5 & 16.9 & 17.5 & 18.0 & 18.7 & 20.3 & 22.3 & 23.6 & 24.6 & 26.4 & 27.7 \\
\hline 16.5 & -1.66 & 20.4 & 0.128 & 16.7 & 17.0 & 17.6 & 18.1 & 18.8 & 20.4 & 22.4 & 23.7 & 24.7 & 26.4 & 27.7 \\
\hline 17 & -1.69 & 20.5 & 0.126 & 16.8 & 17.2 & 17.8 & 18.2 & 18.9 & 20.5 & 22.5 & 23.8 & 24.8 & 26.5 & 27.8 \\
\hline 17.5 & -1.71 & 20.6 & 0.125 & 16.9 & 17.3 & 17.9 & 18.3 & 19.0 & 20.6 & 22.6 & 23.8 & 24.8 & 26.5 & 27.8 \\
\hline 18 & -1.74 & 20.7 & 0.124 & 17.0 & 17.3 & 18.0 & 18.4 & 19.1 & 20.7 & 22.6 & 23.9 & 24.9 & 26.6 & 27.9 \\
\hline
\end{tabular}




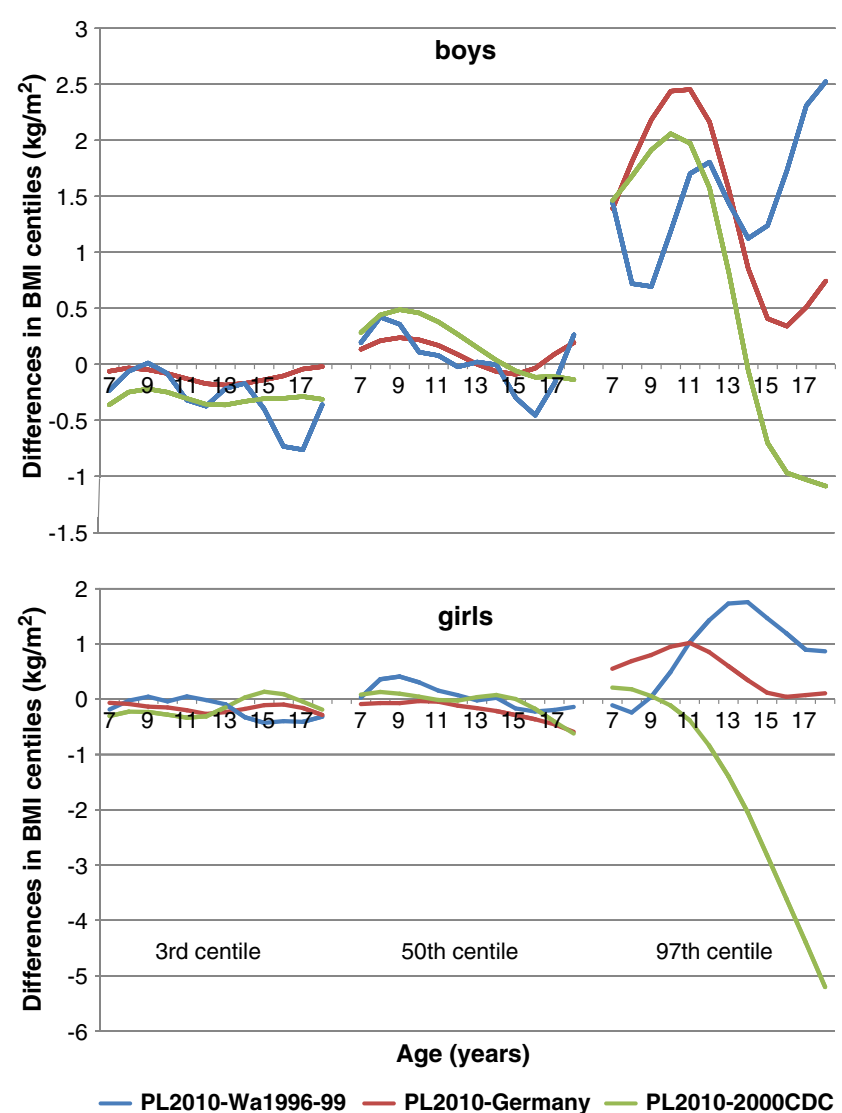

Fig. 3 Comparison of selected centiles of four BMI references. PL2010 reported OLAF study BMI references, PL1996-99 Warsaw BMI references [24], Germany BMI references for German children and adolescents [18], 2000CDC BMI references of the Centers for Disease Control and Prevention [19]

The most popular growth references used until recently in Poland were developed for the population of Warsaw in the years 1996-1999 [27]. A recent comparison of the OLAF study on height with the Warsaw height reference showed that height $z$-scores were on average 0.08 and 0.01 in the case of boys and girls, respectively [24]. This indicates that the height references presented here, based on a nationally representative sample (including children from rural areas, who in the late 1980s were smaller compared with their urban counterparts [17]), are very close to the references developed 10 years ago for the urban population. On comparing the ratio of the distance from the 97th weight centile to the median and the distance from the third centile to the median, we noticed increased positive weight skewness in the current reference: the ratio in the case of boys in the reported reference was, on average, 1.99 (in 1996-1999 Warsaw boys the corresponding ratio was 1.82) and in the case of girls the ratio was, on average, 1.92 (in 1996-1999 Warsaw girls the corresponding ratio was 1.73). These observations are similar to the results reported by Flemish researchers [32].

BMI is commonly used in obesity assessment for adults, and its use in children provides a consistent measure across age groups [2]. However, BMI thresholds for overweight and obesity are based on the distribution of the variable in the population and are arbitrarily defined [10]. Differences between populations in BMI distribution do not permit the application of the same overweight threshold. In the current sample of children and adolescents in Poland, at age 18 years, the adult overweight cutoff of $25 \mathrm{~kg} / \mathrm{m}^{2}$ is very close to the 85 th centile in the case of boys (BMI 25.3), but, in the case of girls, the adult cutoff is very close to the 90th centile (BMI 24.9). The differences presented with regard to weight and BMI 97th centiles may indicate that a significant shift of the upper tail of BMI distribution occurred especially in Polish boys at younger ages. Taking into consideration that the prevalence of obesity is increasing steeply in children [16], a strategy of
Table 4 Prevalence (percent and standard error) of overweight and obesity in Polish children and adolescents by sex and age based on the IOTF definition

$S E$ standard error

\begin{tabular}{lccccc}
\hline \multirow{2}{*}{ Age (years) } & \multicolumn{3}{l}{ Boys } & & \multicolumn{2}{l}{ Girls } \\
\cline { 2 - 3 } \cline { 5 - 6 } & Overweight \% (SE) & Obesity \% (SE) & & Overweight \% (SE) & Obesity \% (SE) \\
\hline 7 & $14.0(1.6)$ & $5.3(1.1)$ & & $12.9(1.7)$ & $4.4(1.0)$ \\
8 & $15.5(1.4)$ & $5.9(0.9)$ & & $13.4(1.3)$ & $4.5(0.8)$ \\
9 & $16.8(1.4)$ & $5.2(0.8)$ & & $17.0(1.4)$ & $3.6(0.7)$ \\
10 & $16.5(1.5)$ & $5.9(0.9)$ & & $16.5(1.4)$ & $2.7(0.6)$ \\
11 & $16.7(1.4)$ & $4.4(0.8)$ & & $16.3(1.4)$ & $3.4(0.7)$ \\
12 & $16.9(1.5)$ & $5.5(0.9)$ & & $12.3(1.3)$ & $2.4(0.6)$ \\
13 & $14.8(1.4)$ & $4.5(0.8)$ & & $11.4(1.3)$ & $2.8(0.7)$ \\
14 & $10.7(1.2)$ & $3.5(0.7)$ & & $11.2(1.1)$ & $1.6(0.5)$ \\
15 & $13.3(1.3)$ & $3.0(0.6)$ & & $9.3(1.1)$ & $2.5(0.6)$ \\
16 & $11.3(1.2)$ & $2.3(0.6)$ & & $8.0(0.9)$ & $1.1(0.4)$ \\
17 & $13.0(1.2)$ & $3.0(0.6)$ & & $8.8(0.9)$ & $1.8(0.4)$ \\
18 & $14.1(1.2)$ & $3.9(0.7)$ & & $7.1(0.8)$ & $2.1(0.4)$ \\
\hline
\end{tabular}


"freezing" the BMI charts at a particular moment in time and then using them to quantify obesity changes over time is recommended, instead of updating centile charts for BMI on a regular basis [6]. In the case of Poland, which, until now, did not have a nationally representative BMI reference for children, options other than "freezing" existing references should also be considered. For example, using the overweight and obesity definition as proposed by the IOTF, i.e., with the use of cut-off points linking BMI values in childhood with the adult overweight and obesity definition [7], or using the WHO definition of overweight and obesity in childhood and adolescence [8]. The presented height, weight, and BMI references are based on a current, nationally representative sample of Polish children and adolescents without known disorders affecting growth. These growth references represent an improvement over the references used until recently in Poland. Our data also indicate that there exist significant differences between country-specific growth references. The growth charts are available in Polish and English and can be downloaded free of charge from the web site: http://www.czd.pl/olaf.

Acknowledgements The OLAF study was supported by a grant from Iceland, Liechtenstein, and Norway through the EEA Financial Mechanism and the Norwegian Financial Mechanism, and the Ministry of Science and Higher Education of Poland; grant number: PL0080. The OLAF Study Group: Medical University of Białystok: Agnieszka Rybi-Szumińska, Michał Szumiński, Katarzyna TarantaJanusz, Edyta Tenderenda; Regional Children's Hospital in Bydgoszcz: Beata Jasińska; Medical University of Gdańsk: Piotr Czarniak, Dominik Świętoń, Przemysław Szcześniak; Jagiellonian University Medical College in Kraków: Monika Miklaszewska, Katarzyna Wilkosz, Katarzyna Zachwieja, Iwona Ogarek; Medical University of Lublin: Marek Majewski, Aleksandra SobieszczańskaDroździel, Izabela Szlązak, Paweł Szlązak; Polish Mother's Memorial Hospital Research Institute in Łódź: Monika Pawlak-Bratkowska, Anna Półtorak-Krawczyk; District Hospital in Kędzierzyn-Koźle: Danuta Gmyrek; Poznan University of Medical Sciences: Jolanta Sołtysiak; Regional Children's Hospital in Toruń: Roman Stankiewicz, Sława Zbucka; The Children's Memorial Health Institute in Warsaw: Robert Pietruczuk, Agnieszka Różdżyńska, Jan Szpor, Anna Świąder; Wroclaw Medical University: Jacek Kleszczyński, Magdalena Naleśniak, Anna Wawro, Irena Wikiera-Magott; Medical University of Silesia: Piotr Adamczyk, Tatiana Augustyn-Iwachów, Beata Banaszak, Omar Bjanid, Katarzyna Broll-Waśka.

We would like to thank Professor Tim J. Cole for the consultation of the 2010 growth references for Polish school-aged children and adolescents.

The authors declare that they have no personal financial relationships with the organizations sponsoring the study.

Open Access This article is distributed under the terms of the Creative Commons Attribution Noncommercial License which permits any noncommercial use, distribution, and reproduction in any medium, provided the original author(s) and source are credited.

\section{References}

1. Aksu F, Schnakenburg KV (1980) Percentilkurven von Körpergrösse und-Gewicht Türkischer Jungen und Mädchen Der. Kinderartz 11:199-205

2. Barlow SE, Dietz WH (1998) Obesity evaluation and treatment: expert committee recommendations. Pediatrics 102(3):e29 URL: http://www.pediatrics.org/cgi/content/ full/102/3/e29 Accessed 25 April 2010

3. Central Statistical Office (2008) Statistical Yearbook of Republik of Poland 2008, Warsaw

4. Cole TJ (1990) The LMS method for constructing normalized growth standards. Eur J Clin Nutr 44:45-60

5. Cole TJ (2006) Growth references and standards. In: Cameron N (ed) Human growth and development. Academic, London, pp 383-413

6. Cole TJ, Rolland-Cachera F (2002) Measurement and definition. In: Burniat W, Cole T, Lissau I, Poskitt E (eds) Child and adolescent obesity: causes and consequences, prevention and management. Cambridge University Press, Cambridge, p 17

7. Cole TJ, Bellizzi MC, Flegal KM et al (2000) Establishing a standard definition for child overweight and obesity worldwide: international survey. BMJ 320:1240-1243. doi:10.1136/ bmj.320.7244.1240

8. de Onis M, Onyango AW, Borghi E et al (2007) Development of a WHO growth reference for school-aged children and adolescents. Bull World Health Organ 85:660-667. doi:10.1590/S004296862007000900010

9. EUROSTAT http://epp.eurostat.ec.europa.eu/tgm/table.do?tab= table\&init $=1 \&$ plugin $=1$ \&language $=$ en $\&$ pcode $=$ tsieb010 Accessed 20 April 2010

10. Fayter D, Nixon J, Hartley S et al (2007) A systematic review of the routine monitoring of growth in children of primary school age to identify growth related conditions. Health Technol Assess 11:iii,xi-xii,1-163

11. Fredriks AM, van Buuren S, Jeurissen SE et al (2003) Height, weight, body mass index and pubertal development reference values for children of Turkish origin in The Netherlands. Eur J Pediatr 162:788-793. doi:10.1007/s00431-003-1292-x

12. Fredriks AM, van Buuren S, Jeurissen SE et al (2004) Height, weight, body mass index and pubertal development references for children of Moroccan origin in The Netherlands. Acta Paediatr 93:817-824. doi:10.1111/j.1651-2227.2004.tb03024.x

13. Free download: http://homepage.mac.com/tjcole/FileSharing1.html

14. Gelander L (2006) Children's growth: a health indicator and a diagnostic tool. Acta Paediatr 95:517-518. doi:10.1080/ 08035250600644747

15. Grote FK, van Dommelen P, Oostdijk W et al (2008) Developing evidence-based guidelines for referral for short stature. Arch Dis Child 93:212-217

16. Guillaume M, Lissau I (2002) Epidemiology. In: Burniat W, Cole T, Lissau I, Poskitt E (eds) Child and adolescent obesity: causes and consequences, prevention and management. Cambridge University Press, Cambridge, $\mathrm{p} 44$

17. Hulanicka B, Brajczewski C, Jedlińska W et al (1990) City-TownVillage, growth of children in Poland in 1988. Monografie Zakładu Antropologii PAN, Wrocław

18. Kirchengast S, Schober E (2009) Growth charts in the globalizing world: a new challenge for anthropologists and paediatricians. Acta Med Litu 16:76-82. doi:10.2478/v10140-009-0011-y

19. Komlos J (1994) Preface. In: Komlos J (ed) Stature, living standards, and economic development. Essays in anthropometric history. University of Chicago Press, Chicago, pp 9-11 
20. Kosmowski W (1894) O wzroście i wadze dzieci klas biednych w Warszawie. Odb. z Medycyny, Druk K. Kowalewskiego, Warszawa

21. Kromeyer-Hauschild K, Wabitsch M, Kunze D et al (2001) Perzentile für den Body-mass-Index für das Kindes- und Jugendalter unter Heranziehung verschiedener deutscher Stichproben Monatsschr Kinderheilkd 149:807-818

22. Kuczmarski RJ, Ogden CL, Guo SS et al (2002) 2000 CDC growth charts for the United States: methods and development. Vital Health Stat 11:1-190

23. Kulaga Z, Krzyżaniak A, Palczewska I et al (2007) Rapid westernization of Warsaw (Poland) children obesity prevalence comparison with Australian and USA population. Ann Diag Peadiatr Pathol 11:71-76

24. Kulaga Z, Litwin M, Tkaczyk M et al (2010) The height-, weight-, and BMI-for-age of Polish school-aged children and adolescents relative to international and local growth references. BMC Public Health 10:109. doi:10.1186/1471-2458-10-109

25. Nyström Peck M, Lundberg O (1995) Short stature as an effect of economic and social conditions in childhood. Soc Sci Med 41:733-738

26. OECD http://stats.oecd.org Accessed 20 April 2010

27. Palczewska I, Niedzwiedzka Z (2001) Somatic development indices in children and youth of Warsaw. Med Wieku Rozw 5 (Suppl 1):18-118

28. Pan H, Cole TJ (2000) LMSchartmaker, a program to construct growth references using the LMS method Version $2.42 \mathrm{http} / /$ www.healthforallchildren.co.uk. Accessed 25 April 2010
29. Pan H, Cole TJ (2004) A comparison of goodness of fit tests for age-related reference ranges. Stat Med 23:1749-1765. doi: $10.1002 / \operatorname{sim} .1692$

30. Poskitt EM (1995) Defining childhood obesity: the relative body mass index (BMI). European Childhood Obesity group. Acta Paediatr 84:961-963

31. Ratha D, Xu Z (2008) Migration and remittances factbook. World Bank. http://siteresources.worldbank.org/INTPROSPECTS/ Resources/334934-1199807908806/Poland.pdf. Accessed 15 May 2010

32. Roelants M, Hauspie R, Hoppenbrouwers K (2009) References for growth and pubertal development from birth to 21 years in Flanders. Belgium Ann Hum Biol 36:679-693. doi:10.3109/ 03014460903049074

33. Royston P, Wright EM (2000) Goodness-of-fit statistics for agespecific reference intervals. Stat Med 19:2943-2962. doi:10.1002/ 1097-0258(20001115)19:21<2943::AID-SIM559>3.0.CO;2-5

34. Suligowski F (1887) Kilka słów o pomiarach antropometrycznych młodzieży gimnazjum męzkiego w Radomiu Medycyna 15:512-516

35. Tanner JM (1987) Growth as a mirror of the condition of society: secular trend and class distinction. Acta Paediatr Jpn 29:96-102

36. Towne B, Demerath EW, Czerwinski SA (2006) The genetic epidemiology of growth and development. In: Cameron $\mathrm{N}$ (ed) Human growth and development. Academic, London, pp 103-137

37. Wolański N (1975) Metody kontroli i normy rozwoju dzieci i młodzieży. PZWL, Warszawa

38. World Economic Outlook http://www.imf.org/external/pubs/ft/ weo/2009/02/weodata/groups.htm\#oem Accessed 20 April 2010 